\title{
Discurso del Sr. Rodrigo T. Rojas Mackenzie*
}

Aludamos el estar de nuevo en territorio académico de la Universi-
dad de Concepción, especialmente cuando el motivo es la presentación de este libro escrito por Fabienne Bradu y editado bajo el sello del Fondo de Cultura Económica, histórica institución de la cultura mexicana a la que desde su fundación en 1934 tanto le debemos los lectores de Hispanoamérica y que fuera, además, la casa editorial de Gonzalo Rojas.

El libro titulado Cambiemos la aldea reúne gran parte de los documentos, hoy ya históricos, que ilustran el ejercicio de lo que fue un método de conocimiento de Chile y de América, un sistema de autoanálisis al que escritores e intelectuales de Chile, de América y del mundo fueron convocados desde la Universidad de Concepción hace más de medio siglo.

Algunos han reparado en el hecho de que la demorada publicación de estos textos tenga lugar justamente en estos días de insumisión nacional en que la sociedad chilena demanda formas más justas y dignas de existencia. Indudablemente, esta simultaneidad, al no responder al principio de causaefecto, nos hace pensar en designios de otra índole. En el azar objetivo, por ejemplo, ese principio tan caro al surrealismo que fuera enunciado por André Breton, o bien en aquella concatenación de viso taoísta propuesta por C. G. Jung, la de la llamada sincronicidad, conceptos ambos que tratan de explicar algunas de esas aparentes simples coincidencias que por la carga del valor emocional que contienen se vuelven altamente significativas.

Hay, sin embargo, un hecho innegable -probablemente relacionado con el aire renovador de estos tiempos- que ha sido fundamental para la materialización de este libro: me refiero a la decisión de las nuevas autoridades

* Neurólogo y Psiquiatra. Director clínico Departamento de Neurorrehabilitación, Wicker-Klinik, R.F. de Alemania. Director y representante para Europa de la Fundación de Estudios Iberoamericanos Gonzalo Rojas. Coordinador de la publicación de libros de Gonzalo Rojas en idiomas extranjeros. 
académicas de la Universidad de Concepción de cumplir con una deuda pendiente que esta Casa de Estudios tenía con el acervo cultural de Chile y de América, deuda que con motivo de la edición de este libro no han vacilado en saldar al asumir la co-edición de la obra.

Son casi sesenta los años transcurridos desde que al cierre de la Escuela Internacional de Verano de 1962 Gonzalo Rojas anunciara en Concepción que había recibido desde México la propuesta del FCE para publicar los textos de las ponencias y de los debates de los Diálogos, a los que bajo la denominación de Imagen de América latina e Imagen del hombre, habían concurrido aquel enero escritores, artistas, filósofos, sociólogos, juristas, arquitectos y científicos del mundo.

La propuesta mexicana provenía directamente del entonces Director de la editorial, Arnaldo Orfila Reynal, intelectual señero de ese país, quien en el otro extremo del continente estaba al tanto de la tradición inaugurada a partir de 1958 en esta lejana Casa de Estudios, de organizar amplias convocatorias intelectuales en sus espacios académicos, primero de Chile, luego de América en 1960 y ahora del mundo, en 1962.

Desafortunadamente, decisiones condicionadas por la política universitaria de la época hicieron que las autoridades académicas de aquel plazo obturaran el proyecto al negarse a atender la generosa y visionaria oferta mexicana.

A diferencia de lo acontecido con los documentos de los primeros Encuentros de escritores chilenos celebrados en Concepción y en Chillán en 1958 , los que fueron publicados prontamente en un volumen especial de la revista Atenea de la Universidad, ahora, cuatro años después, la polarización ideológica de Latinoamérica hacía que a escritores e intelectuales que reflexionaran sobre aspectos tales como la creación literaria y la responsabilidad del escritor o sobre la imaginación y la autonomía cultural del continente, se les considerara desde la llamada institucionalidad: "activistas" sospechosos de querer subvertir el orden imperante.

Quienes vivimos el contexto de ese plazo sabemos en qué grado, entre el 58 y el 62, en el marco de la llamada Guerra fría, acontecimientos como la Revolución cubana de 1959, la descolonización del continente africano, la guerra del Vietnam y la construcción del Muro de Berlín, por mencionar hechos señeros, habían crispado la convivencia social en los países de Occidente y cómo el ejercicio de la censura llegó a ser una práctica frecuente de los frentes en conflicto. 


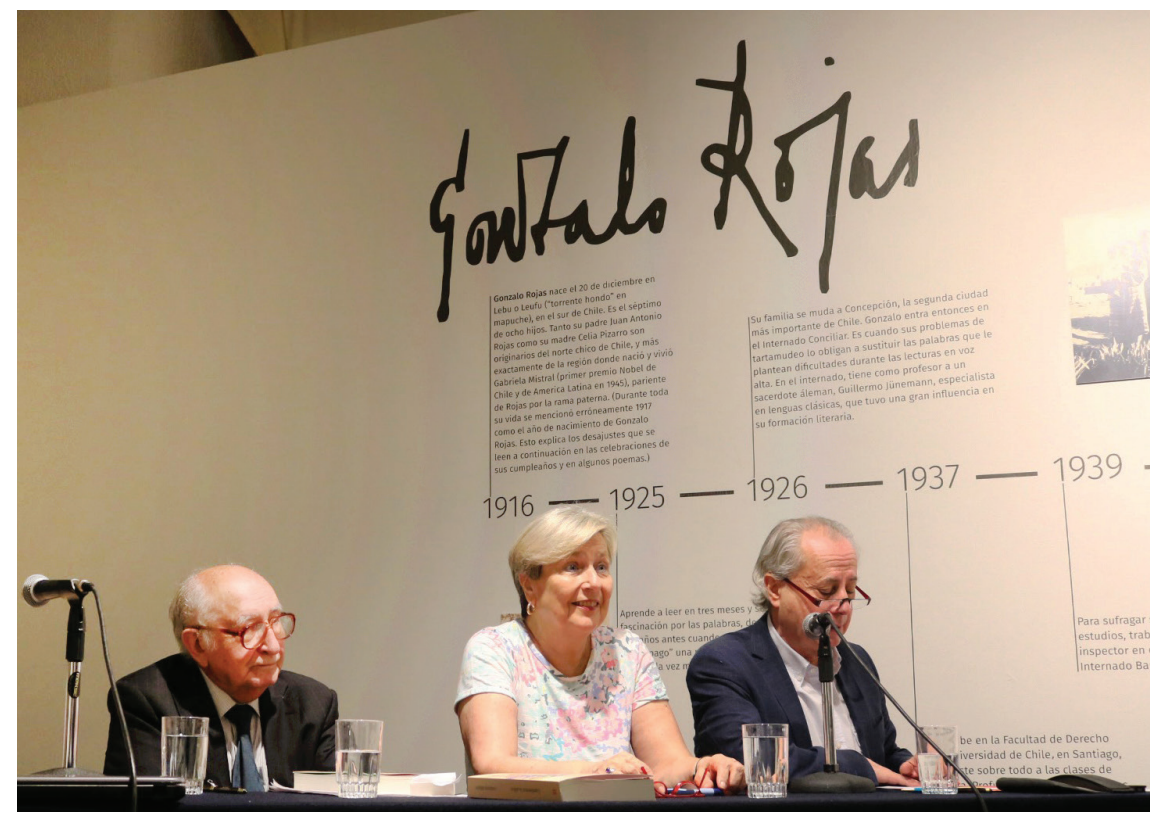

Rodrigo T. Rojas Mackenzie, director de la FGR, acompañado de Fabienne Bradu y del poeta Pedro Lastra. Concepción, 18 de enero de 2020.

En cuanto a las actas del Encuentro de escritores americanos celebrado en 1960, las que por vez primera se recogen también en este libro, tampoco fueron publicadas oportunamente, aunque no por razones políticas sino telúricas: el 21 de mayo de ese año el mayor cataclismo de la historia detuvo a las 6.05 de la mañana el reloj del campanil y al mismo tiempo también por largo tiempo la marcha de la Universidad.

Pero hoy, aunque demorado, este volumen ve la luz y lo hace por fin con los sellos de la editorial mexicana y de la Universidad.

Ahora, en el umbral de los años 20 del siglo XXI, gracias a la difícil tarea -difícil por larga y minuciosa- que desde hace años ha llevado a cabo Fabienne Bradu, de recopilación y edición de los manuscritos y de transcripción de la palabra escrita y oral de los participantes, sí que podremos tener acceso al pensamiento expresado y defendido libremente en Concepción, sin limitaciones ideológicas, políticas, o religiosas de naturaleza alguna, por aquellos hombres y mujeres intelectuales de nuestro siglo XX.

Este libro, además de contener una representativa selección de lo escrito y de lo dicho por ellos, nos ofrece dos documentos que iluminan su lectura: 
El primero, un texto de fundamento y de notable valor testimonial que es el prólogo escrito por Pedro Lastra, poeta y maestro de las letras de Chile y América quien, siendo entonces un joven escritor, además de haber participado en los encuentros tuviera también un activo rol en la gestación de los mismos.

La palabra de Pedro antecede al segundo escrito, un acucioso ensayo de Fabienne Bradu que sitúa la voz de los escritores de un modo muy riguroso y acertado en el contexto histórico y social del acontecer literario y académico del Chile y de la América de entonces.

Su larga dedicación al estudio de la obra tanto poética como también prosística-testimonial de Gonzalo Rojas y su condición de biógrafa del mismo, han sido factores fundamentales en la feliz plasmación de este libro que a partir de hoy enriquece el registro de la historia cultural del continente.

El 14 de mayo de 2002 al pronunciar la lección inaugural del año académico de la Universidad de Concepción, Gonzalo Rojas apuntaba directamente: "Ya no hay vestigio de esos bellísimos eneros. Ya no hay 58, ya no hay 62, como si el cataclismo de la desmemoria hubiera arrasado con esos diálogos". También agregaba: "Porque si hay Universidad de nuestra América que haya apostado al diálogo constructivo y disidente al amparo de la imaginación y del coraje, del rigor y la lucidez, esa es la nuestra. Ahí están los Encuentros sucesivos de escritores y pensadores nacionales e internacionales en cada enero ardiente de los 50 y 60 del siglo anterior, todo lo cual, inédito hasta estas fechas, constituye un capítulo memorable de nuestra historia cultural, que exige continuidad, porque lo que no tiene continuidad no tiene realidad". Qué duda cabe que la demanda que esas palabras contenían tiene hoy en la realidad de este libro de Fabienne Bradu la respuesta que merece.

Mucho se ha dicho sobre los encuentros de Concepción más allá de las fronteras nacionales: Carpentier los comparó a las reuniones de la Abadía de Pontigny en la Francia de hace un siglo; Robert Merton, el sociólogo norteamericano, llegó a afirmar que el 62 había participado en la Universidad de Concepción en una especie de Parlamento del mundo; Carlos Fuentes y José Donoso creyeron ver en ellos el nacimiento del Boom de las letras latinoamericanas. En Chile muchas voces de escritores celebraron que a partir de ellos se había puesto fin a la insularidad de la literatura nacional al demostrar que en la nación chilena había otros valores y otras formas de expresión más allá de la Mistral, Huidobro y Neruda. 
Gonzalo Rojas, por su parte, a modo de contenido balance, a lo que llegó fue a afirmar que: "de esos encuentros lo que surgió fue una conciencia del lenguaje y una conciencia del límite, además de una conciencia social del oficio literario del más alto vuelo".

Y es de eso, a mi juicio, de lo que primordialmente da prueba este libro, al que tendrán en el futuro que estar volviendo quienes estudien la historia cultural de Chile y América en el siglo XX, como en su oportunidad lo hicieran los de ese siglo, al consultar los documentos del siglo anterior, en especial los relativos a lo acontecido en las letras chilenas a partir de 1842.

La aparición de este volumen es también un justo y necesario reconocimiento a la labor de otros hombres de letras de la Universidad de Concepción que acompañaron a Gonzalo Rojas en su tarea fundadora de Escuelas de temporada y de Misiones culturales por el interior de Chile, de Talleres de literatura, y de Encuentros y de Diálogos de escritores e intelectuales: Alfredo Lefebvre, Juan Loveluck, René Cánovas, Luis Muñoz, Gastón von dem Busch, Jaime Concha, Jaime Giordano, Romano Vallebuona, nombres que no podemos dejar de recordar hoy en esta aula de la Universidad de Concepción.

Permítanme, por último, situar en el ejercicio memorístico de esta tarde un hecho de la vida universitaria de Concepción ocurrido a mediados de 1953, el que no ha sido aun registrado en crónica alguna y que bien pudiera constituir el comienzo de la historia de la que hoy aquí estamos hablando:

La primera constancia que hay en la prensa de Concepción de la tarea cultural fundadora inaugurada por estas figuras de la Universidad, es relativa a unas jornadas que, a poco de incorporarse a la docencia, propusiera Gonzalo Rojas y que con el título de "Viaje por la poesía de Chile", fueron organizadas con el patrocinio de la Federación de Estudiantes Universitarios de Concepción, presidida entonces por Galo Gómez Oyarzún, y que tuvieron lugar en el Aula Magna de la Facultad de Educación ante aproximadamente 300 personas, las que asistieron a oír las intervenciones de Gonzalo Rojas, del escritor Daniel Belmar, del ensayista Alfredo Lefebvre y del hombre de teatro Jorge Lillo.

La resonancia de la experiencia vivida por el público mayoritariamente estudiantil fue tal, que los diarios de los días posteriores informan profusamente de la réplica de aquel diálogo en otras ciudades del sur que habían solicitado la repetición del mismo. 
Es de justicia recordar este acontecimiento para destacar que, como a menudo ocurre en el curso de la historia, también en los inicios de este proceso renovador de la vida cultural y académica, fueron los jóvenes de esta Universidad del interior de Chile quienes primero supieron recibir y aquilatar aquel aire nuevo "No solo para respirarlo, sino también para vivirlo".

De ello dan fe unas palabras que a mi juicio retratan plenamente la dimensión de lo que, para quienes fuimos testigos de esa hora de la vida cultural del continente, fue nuestra vivencia al asistir a las memorables jornadas que en esos años tenían lugar en esta universidad del sur del mundo. Son líneas escritas por la escritora y ensayista chilena Ana Pizarro, exalumna de esta universidad:

En los primeros Encuentros de escritores chilenos y americanos, nosotros los jóvenes de una provincia del sur del mundo teníamos la sensación de estar participando en las grandes discusiones culturales del continente en un momento privilegiado.

Esos días serían definitivos para nosotros.

Estábamos tranquilos en nuestra vida parroquiana y, de repente, Gonzalo Rojas nos arrancó de la provincia y nos hizo sentir, nos arrojó al universo.

Creo que entonces descubrimos la sensación de pertenecer a un espacio mayor que el del Bío-Bío, aquel río sigiloso que tanto amamos. (Ana Pizarro)

Nuestro reconocimiento entonces a la autora del libro Cambiemos la aldea, quien al rescatar este capítulo casi olvidado de nuestro siglo XX cultural, no solo enriquece la memoria histórica de Chile, sino también reivindica el reflexionar responsable y la imaginación como fundamentos necesarios para la construcción de un mañana más digno, que es por lo que pugna en estos días nuestro pueblo. 